Received: 03/03/2019

Revision: 27/11/2019

Accepted: 01/12/2019

OnlineFirst:28/01/2020

\title{
The Levels of Students' Feeling of Rightness (FOR) in Solving Polygon Perimeter Problems
}

\section{Puguh Darmawan}

Dr. Candidate, Fakultas Matematika dan Ilmu Pengetahuan Alam, Universitas Negeri Malang, puguh.darmawan.1603119@students.um.ac.id

\section{Purwanto}

Prof., Fakultas Matematika dan Ilmu Pengetahuan Alam, Universitas Negeri Malang, purwanto.fmipa@um.ac.id

\section{Nengah Parta}

Dr., Fakultas Matematika dan Ilmu Pengetahuan Alam Universitas Negeri Malang, nengah.parta.fmipa@um.ac.id

\section{Susiswo}

Dr., Fakultas Matematika dan Ilmu Pengetahuan Alam, Universitas Negeri Malang, susiswo.fmipa@um.ac.id

This research aimed to describe the levels of feeling of rightness (FOR) of students. This research used a qualitative method with an explorative type. The subjects of this research were 3 students of 5th grade selected from 77 other students in Indonesia. In uncovering FOR subject of this research, instruments were used in the form of problems about the open-ended polygon perimeter and interview guidelines. The data of this research were the subjects' answers to the problems of polygon perimeter and the results of interviews with subjects related to these answers. The data were analyzed using the FOR subject level indicator rubric. There were three levels of FOR which were the findings in this research, namely low, medium, and high. Low FOR level was indicated by the answers crossed out and the objectives or goal changed. Medium FOR level was indicated by crossed out answers, objectives or goals changed, problems text read repeatedly, indecisive statements about the truth of the answers that have been generated, and doubts in determining the steps to be taken. High FOR level was indicated by answers that were not crossed and goals that were not changed.

Keywords: dual-process theory, problem-solving, polygon, perimeter, feeling of rightness, learning

Citation: Darmawan, P., Purwanto, Parta, I. N., \& Susiswo (2020). The Levels of Students' Feeling of Rightness (FOR) in Solving Polygon Perimeter Problems. International Journal of Instruction, 13(2), 549-566. https://doi.org/10.29333/iji.2020.13238a 


\section{INTRODUCTION}

In everyday life, as well as in learning, students often face problems whose solutions require conceptual knowledge of the area and perimeter of a polygon. Conceptual knowledge is knowledge about integrated and functional relationships between concepts (Achmetli et al., 2018; Susiswo, 2015). The concept of area and perimeter of a polygon also underlies other concepts (Kow\& Yeo, 2008). Other concepts based on the concept of area and perimeter of a polygon includes volume and surface area (Ministry of Education and Culture, 2013; NCTM, 2000). In addition, the concept of area and perimeter of a polygon also has a very broad application in daily life (Kow\& Yeo, 2008), such as in tiling houses, making soccer fields, making race tracks and so on. For this reason, it is important for students to have conceptual knowledge about the area and perimeter of a polygon.

The ownership of conceptual knowledge by students can be traced when students solve problems. This happens because there is an application of knowledge that is owned, in an effort to produce solutions (Căprioară, 2015; NCTM, 2009; Tambychik et al., 2010). In addition, to be able to solve problems, students must also have procedural knowledge that supports the conceptual knowledge (Borodin, 2016; Kryjevskaia, 2014; Leron \& Hazzan, 2009; Susiswo, 2015). Procedural knowledge is knowledge about how to do a procedure or algorithm and knowledge of mathematical symbols (Achmetli et al., 2018; Susiswo, 2015). Therefore, if students already have conceptual and procedural knowledge, students should be able to solve the problems they face (Borodin, 2016; Kryjevskaia, 2014; Leron \& Hazzan, 2009; Susiswo, 2015).

Grade 5 is the lowest formal education level where students have experience in learning the concepts of area and perimeter of a polygon, as well as the interrelationship between the two concepts (Ministry of Education and Culture, 2013; Musser, Burger et al., 2011; NCTM, 2000). From the learning experience, it is possible to have conceptual and procedural knowledge possessed by grade 5 students. For this reason, grade 5 students should be able to solve problems regarding the area and perimeter of a polygon. However, the researcher finds data showing the opposite condition. Similar findings have also been revealed in previous research, including Babai, Younis, \& Stavy (2014), Musser, Burger, \& Peterson (2011), Kow \& Yeo (2008), and Mulligan et al., (2005). However, the research that has been done only focuses on the answers generated by students (the number of correct answers and the number of incorrect answers) and not on the mental process of producing those answers. In fact, the mental process of producing an answer actually becomes the determining factor for producing a right or wrong answer. For this reason, the focus of this research is the mental process of producing answers.

In fact, the ability of $5^{\text {th }}$ grade students to solve problems related to area and perimeter of a polygon is very important as a basis for learning related concepts at a higher level, as well as to be applied in everyday life. This condition is shown by one of the answers to grade 5 students on the problem presented in Figure 1 below. 
The area of a quadrilateral is $12 \mathrm{~cm}^{2}$. If one side has a length of $4 \mathrm{~cm}$, what is the perimeter?

Figure 1

Problems of the Perimeter of a Polygon

The following is one of the answers of grade 5 students on the problem above.

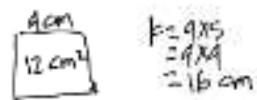

A

B

Figure 2

One of the Answers of Grade 5 Students

Based on the answer above, it was known that the student concluded that the quadrilateral referred to in the problem is aquadrilateral, which is indicated by the

writing of the formula of square perimeter, namely $K=4 \times s$ (figure 2 part B). This was also confirmed by students, when the researchers conducted an interview, that the

meaning of $K=4 \times s$ is the perimeter of a square equal to four times the length of its side.

Then, the researchers asked questions to detect students' conceptual and procedural knowledge, such as the following.

Researcher : "Mention the various quadrilateral you know!"

Student : "Square and rectangle."

Researcher : "How do you determine the area?"

Student : "You can use the formula, for example the area formula of a square= (length of side $)^{2}$, the area formula of a rectangle =length $\times$ width"

Researcher : "How do you determine the perimeter?"

Student : "Just add the length of all sides, or use the formula."

From the results of the interview above, there are indications that students' conceptual and procedural knowledge are sufficient to solve the problem given by the researchers. One indication is the student's statement about the perimeter of the quadrilateral, which is the sum of all the lengths of the sides. However, the student produced the wrong answer because the student immediately assumed the rectangle was a square. This is indicated by student's statements during interviews such as the following.

Researcher: "Are you asked to determine the perimeter of a quadrilateral or the perimeter of a square?”

Student : : "Quadrilateral, but only the length of one side is known, it's usually a square, sir." 


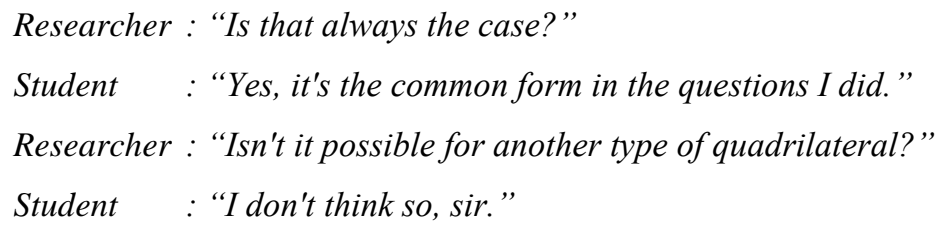

Based on dual-process theory, in addition to conceptual or procedural knowledge, there are two mental processes that need to be managed properly, so students can produce solutions (Babai et al., 2015; Bellini-leite, 2017; Borodin, 2016; De Neys, 2018; Durning et al., 2015). These two mental processes are system 1 and system 2. The characteristics of system 1 process are the same as intuition or heuristic, and the process characteristics of system 2 are the same as analytical thinking (Bago \& De Neys, 2017; Borodin, 2016; Imbir, 2016).

The characteristics of system 1 process are fast, allowing parallel, automatic, associative or matching process, and not flexible. On the other hand, the system 2 characteristics are slow, serial, controlled, systematic and flexible (Bago\& De Neys, 2017; Bellini-leite, 2017; Handley \& Trippas, 2015; Imbir, 2016; Stanovich \& Evans, 2014). The conditions experienced by one of the $5^{\text {th }}$ grade students above can be explained by dualprocess theory.

Based on dual-process theory, after the stimulus (in this case, the problem given by the researchers) belongs to the sensory register and is given attention by students, then the students' system 2 is active to perform shallow analysis (De Neys, 2012, 2014; Dujmović \& Valerjev, 2018). The meaning of shallow analysis is an analysis that does not pay attention to information as a whole from the problem and takes place quickly (Ackerman \& Thompson, 2017; Martin \& Sloman, 2013). In other words, students only give attention to certain information, and ignore information that is considered insignificant. This is triggered by the salience of the attention given information (Babai et al., 2015; Lamy et al., 2004; Lem, 2015; Zink et al., 2004) or because of familiar feelings students towards that information (Fu et al., 2010; Mihaela \& Voica, 2008).

Furthermore, the results of the shallow analysis then produce an incomplete structure of problems (Martin \&Sloman, 2013). The incomplete structure of problems triggers the active system 1 . Next, system 1 associates or matches the incomplete structure of the problems with the mental structure that has been stored in long-term memory. After matching, immediate responses are produced in the form of written answers, without going through processes in working memory (Ackerman \& Thompson, 2017; Bago \& De Neys, 2017; Borodin, 2016; Banks \& Hope, 2013; De Neys, 2018; Imbir, 2016). The process of producing a response with such a stage is called an automatic process (Evans, 2011).

The response generated by system 1 is always accompanied by a feeling of rightness (FOR) with a certain level (Ackerman \& Thompson, 2017; Thompson \& Morsanyi, 2012; Trippas et al., 2017). Furthermore, if the level of FOR students is high, then without feeling the need to check again or without feeling the need to reactivate system 
2, students are convinced that the answer is correct (Ackerman \& Thompson, 2017; Fu et al., 2010; Lin et al., 2013; Martin \& Sloman, 2013). Such conditions tend to make students produce wrong answers. Therefore, re-involvement of system 2 is very important (Prawita et al., 2019). For this reason, there is a need for in-depth research on the factors that trigger the active system 2 (Babai et al., 2015; Babai et al., 2014; Dujmović \& Valerjev, 2018).

Active system 2 is very important to provide an evaluation of the response generated by system 1, so that the potential for the occurrence of errors can be reduced. The main factor that determines the active system 2 after system 1 active is FOR (Ackerman \& Thompson, 2017; Thompson et al., 2018; Trippas et al., 2017). Therefore, research on the FOR is important to do and this research aimed to uncover the FOR level of 5th grade students in solving problems of polygon perimeter.

\section{METHOD}

\section{Design}

This research is a qualitative explorative research. In this research, the researchers presented and explored indications that indicated the high and low of FOR levels.

\section{Subject}

The subjects of this research were 3 students of 5 th grade in Indonesia. The subjects of grade 5 students were chosen because they had experiences in learning the perimeter and area of a polygon. Furthermore, system 1 or system 2 students can be active, if students have a learning experience that is partially or entirely related to the problem at hand (Thompson et al., 2018).

\section{Procedure}

77 students of 5 th grade were selected as prospective subjects. 77 prospective subjects were given problems (see figure 1) to be solved individually. 77 students came from three different classes and also from different elementary schools in Indonesia. Giving problems to students in each class was done on different days. All students were instructed not to erase answers that they considered wrong, but it was enough to cross them out. The purpose of these instructions was to detect changes in students' answers. After completing work, each student was asked to submit the answer to the researchers. Then, the researchers checked the answers of students one-by-one with FOR subject level indicator rubric (Table 1).

From the answers of 77 prospective subjects, there were 3 types of FOR. In this research, those 3 FOR types are termed as low FOR level, medium FOR level, and high FOR level. Based on these types of FOR, there were 68 prospective subjects classified as high FOR level, 4 prospective subjects classified as medium FOR level, and 5 prospective subjects classified as low FOR level. Furthermore, from each FOR level, one prospective subject was randomly selected as a research subject. In a more in-depth search regarding FOR of each subject, further interviews were conducted. 


\section{Data Collection and Data Analysis}

Data in this research were obtained from the written answers to the subject and the results of the interviewer's interviews with the subject. Furthermore, written answers and interview results were analyzed to explore the indications and also the factors that led to the high and low of FOR levels. Written answers to the subject were analyzed with the indicators in table 1 below. The indicator was used to determine the level of FOR.

High FOR is indicated by no change in the answers produced by system 1 (Babai et al., 2015; Durning et al., 2015; Evans, 2011, 2012). In contrast, low FOR level is indicated by the active system 2 and changes in answers (Ackerman \& Thompson, 2017; Thompson et al., 2018, 2011; Thompson \& Morsanyi, 2012). In addition, there are FOR levels that do not fall into those two categories. This happens because this FOR level does not have characteristics that match the two previous FOR categories. The FOR level, one of which is indicated by the emergence of a doubtful subject. In this research, the FOR level will be explored more thoroughly, indicated by the emergence of these doubts, and the researchers gave the term FOR medium level.

Table 1

FOR Subject Level Indicator Rubric

\begin{tabular}{|c|c|c|c|}
\hline $\begin{array}{l}\text { Mental } \\
\text { Activities }\end{array}$ & Goal & $\begin{array}{l}\text { FOR } \\
\text { Level }\end{array}$ & Indicators \\
\hline & $\begin{array}{l}\text { A (Square } \\
\text { Perimeter) }\end{array}$ & High & $\begin{array}{l}\text { 1. Creating a square sketch image } \\
\text { 2. Writing the formula of the square perimeter, which is } \\
\mathrm{K}=4 \times \mathrm{s} \text {, with } \mathrm{s} \text { side length and multiply } 4 \text { by } 4 \\
\text { 3. Having answer } 16 \text { as a square perimeter and does not } \\
\text { change the answer }\end{array}$ \\
\hline System 1 & $\begin{array}{l}\text { B } \\
\text { (Rectangle } \\
\text { Perimeter) }\end{array}$ & High & $\begin{array}{l}\text { 1. Creating a rectangular sketch image } \\
\text { 2. Dividing the area by the known side length, which are } \\
12 \text { and } 4 \\
\text { 3. Stating to be looking for a perimeter square } \\
\text { 4. Writing the formula of the rectangle perimeter, which is } \\
\quad \mathrm{K}=2 \times(\mathrm{p}+1) \text {, with } \mathrm{p} \text { for length and } 1 \text { for width } \\
\text { 5. Writing } \mathrm{K}=2 \times(4+3)=2 \times 7=14 \\
\text { 6. Producing answer } 14 \text { as the perimeter of the rectangle } \\
\text { and not changing the answer }\end{array}$ \\
\hline System 2 & & Medium & $\begin{array}{l}\text { 1. Crossing out the answer to goal A or goal B which is } \\
\text { considered wrong, but being notable to decide the } \\
\text { next step to take (doubtful) } \\
\text { 2. Crossing out all answers to goal A and cross outing all } \\
\text { written answers to goal B, but being not able to } \\
\text { decide the next step to take (doubtful) } \\
\text { 3. Repeatedly reading the problem text after producing } \\
\text { goal A or goal B, but not choosing any steps } \\
\text { afterwards (doubtful) } \\
\text { 4. Being unable to decide decisively, the truth of the steps } \\
\text { that have been taken or the answers that have been } \\
\text { produced }\end{array}$ \\
\hline System 2 & & Low & $\begin{array}{l}\text { 1. Crossing out the written answer to goal A or goal B, } \\
\text { because it is considered wrong } \\
\text { 2. Changing goal A to goal B or changing goal B to goal A }\end{array}$ \\
\hline
\end{tabular}

International Journal of Instruction, April $2020 \bullet$ Vol.13, No.2 


\section{FINDINGS}

In this section, the FOR subject level is presented. There were three levels of FOR which were the findings in this research, namely high, medium, and low. Each of these levels was represented by one subject whose answers are presented below. The following is an explanation of the answers to these subjects.

\section{Subject 1 (Low Level FOR)}

Subject 1 was indicated to involve system 2, after system 1 was active and produced a response. This indication was generally indicated by the change from goal B to goal A. The following are presented the answers to subject 1, with stages I, II, and III.

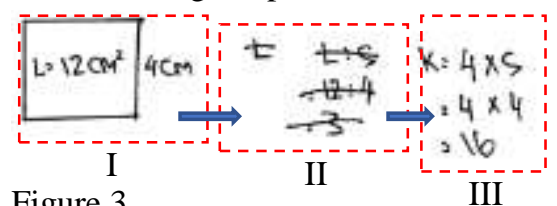

Figure 3

Subject 1's answer

Based on the results of the interview, it was revealed that subject 1 unconsciously immediately drew a quadrilateral sketch after finishing reading the problem text. Without realizing, in this case, it means that subject 1 does not know the purpose of drawing a sketch of the quadrilateral. Unconscious is a characteristic of the system 1 process (De Neys, 2018; Dujmović \& Valerjev, 2018; Thompson et al., 2018). The quadrilateral sketch image can be seen in Figure 3 (I) above. Subject 1 drew a sketch of the rectangle, with the estimated length approaching the actual length, i.e. the length of

one side is $4 \mathrm{~cm}$ and the area is $12 \mathrm{~cm}^{2}$. This is in accordance with the characteristics of system 1, namely globality.

After completing a rectangular sketch drawing, subject 1 divided the area by the length of one known side. This can be seen in Figure 3 (II), subject 1 wrote

$L \div s=12 \div 4=3$, with $L$ area and $s$ side length known. However, subject 1 then crossed out the writing. After being traced by interviews, it turned out that subject 1 felt unsure about the steps. This uncertainty, triggered by one of the information on the problem, is the existence of a known measure of one side. The following are presented excerpts of interview researchers to subject 1 .

Researchers : "Why did you cross out your writing?"

Subject 1 : "That's wrong, sir."

Researchers : "Why is it wrong?"

Subject $1 \quad$ : "I thought it was a rectangle, so I looked for the unknown side length first, but it turned out that it wasn't a rectangle."

Researchers : "How do you find out that it's not a rectangle?" 
Subject 1 : "In the question, it is only mentioned one side length, it must be a square."

Based on the results of the interview above, subject 1 changed goal B to goal A, that is, from the goal of producing a perimeter of the rectangle to a perimeter of the square. After rereading the text of the problem and knowing information about the length of one side, the level of FOR subject 1 becomes low in maintaining goal B. Subject 1 believed that goal A matched the problem faced based on his learning experience.

Next, subject 1 wrote the formula of the perimeter of the square, which is $K=4 \times s$, where $K$ is the perimeter of the square and sis the known side length. The known side lengthis $4 \mathrm{~cm}$, so subject 1 substituted it to the equation $K=4 \times s$, and $K=4 \times 4=16$. The thinking scheme of subject 1 can be described as follows.

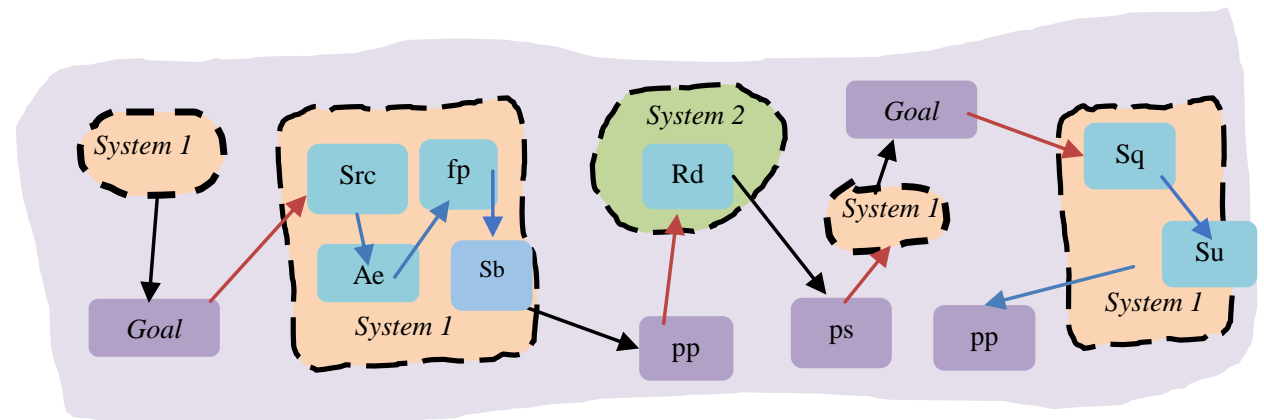

Figure 4

Schematic Thinking of Subject 1

Table 2

Caption

\begin{tabular}{ll}
\hline \multicolumn{1}{c}{ Codes } & \multicolumn{1}{c}{ Meaning } \\
\hline $\mathrm{Src}$ & Creating a rectangular sketch drawing \\
\hline $\mathrm{Ae}$ & Dividing the area by the known side length \\
\hline $\mathrm{fp}$ & Writing the formula of the perimeter of a rectangle \\
\hline $\mathrm{Sb}$ & Substituting the side length, namely 4 and 3 \\
\hline $\mathrm{ppp}$ & The perimeter of a rectangle \\
\hline $\mathrm{Rd}$ & Rereading the text of the problem intentionally/consciously \\
\hline $\mathrm{Ps}$ & Structure of the problem \\
\hline $\mathrm{Sq}$ & Writing the formula of the perimeter of a square \\
\hline $\mathrm{Su}$ & Substituting the side length, which is 4 \\
\hline $\mathrm{pp}$ & The perimeter of a square \\
\hline $\mathrm{Goal} \mathrm{A}$ & Aiming to produce the perimeter of a square \\
\hline $\mathrm{Goal} \mathrm{B}$ & Aiming to produce the perimeter of a rectangle \\
\hline $\mathrm{System}$ 1 & System 1 Process \\
\hline
\end{tabular}




\begin{tabular}{ll}
$\longrightarrow \longrightarrow$ & Pystem2 Process \\
$\longrightarrow$ & Process Transition to results \\
\hline & Results Transition to the next process \\
\hline
\end{tabular}

\section{Subject 2 (Medium Level FOR)}

Subject 2 was indicated to involve system 2, after system 1 was active and produced a response. After doing initial analysis that was shallow and produced an incomplete structure of problems, system 1 subject 2 was active. System 1 was active and a decision appeared to produce goal $\mathrm{B}$, which is the perimeter of a rectangle. After that, without realizing subject 2 immediately drew a quadrilateral sketch with the description

$K=12 \mathrm{~cm}^{2}$. After drawing the square sketch, subject 2

wrote $K: 4=12: 4=3=s=3$. The meaning of the writing is the perimeter of the quadrilateral divided by 4 , resulting in the length of side 3 .

Subject 2 stated if the area and one of side length are known, then the area must be divided by the known side length, to determine an unknown length from the other side. After obtaining different side length from the side whose length is known, subject 2 immediately concluded that the quadrilateral was a rectangular. However, a few moments later subject 2 crossed out the writing, as shown below.
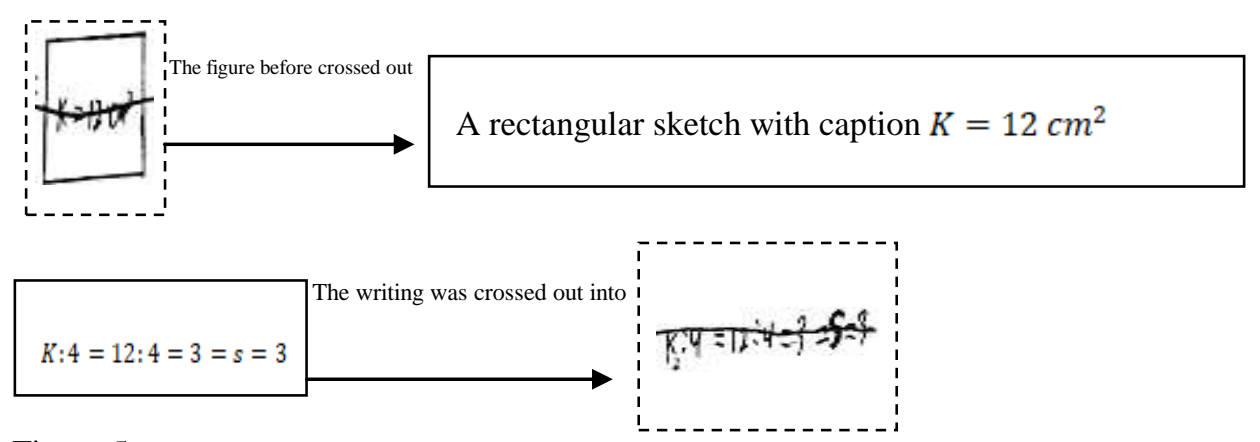

Figure 5

The First Answer of Subject 2

When traced by interview, subject 2 stated the reason for writing down all the answers above because the answer was considered wrong. One of the writings crossed was $K: 4$, where $K$ means perimeter. Subject 2 stated that it should be $L: 4$, with area $L$. Subject 2 realized the writing was wrong, after rereading the text of the problem. Based on the writing errors, subject 2 became alert in answering the question. The emergence of vigilance made subject 2 understood the questions thoroughly. Then, subject 2 drew a rectangular sketch with caption $L: 4$. 
When subject 2 reread the problem text, information about one of the rectangular side length changed the view of the subject 2 . Subject 2 decided to produce goal A, before the process to produce goal $\mathrm{B}$ was completed. This happened when the subject 2

finished writing $L: s=3$, and did not continue the decision to produce goal B. In addition, the process was stopped to produce goal B by subject 2 , also indicated by crossing out of the writing as shown in the image below.
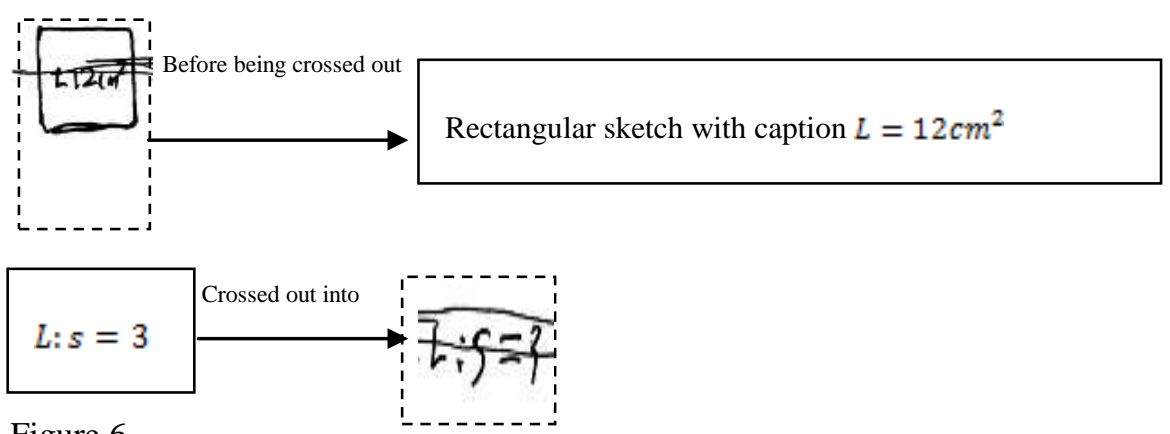

Figure 6

Goal B Which was Stopped

Next, subject 2 immediately wrote $4 \times 4=16$ as the perimeter of the square.

However, subject 2 got back to write. Subject 2 crossed out the writing $4 \times 4=16$, as shown in Figure 7 below.

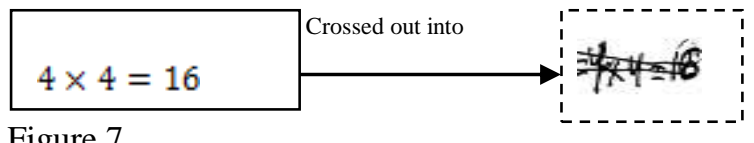

Figure 7

The Answer Which was Crossed Out

Subject 2 stated the reason for the write-off because subject 2 could not decide the correctness of the answer that has been produced. In addition, subject 2 also expressed hesitation in determining the next appropriate step to produce a solution. The state of being doubtful occurred after subject 2 reread the problem text for the third time. Subject 2 stated that there were various types of quadrilateral. However, based on the learning experience, subject 2 stated the solution that best fits the problem of the perimeter of the square. Finally, subject 2 collected the results of the work to the researchers, without decisive decisions and without clear answers. When depicted in the scheme, then the schematic thinking of subject 2 looks like the picture below. 


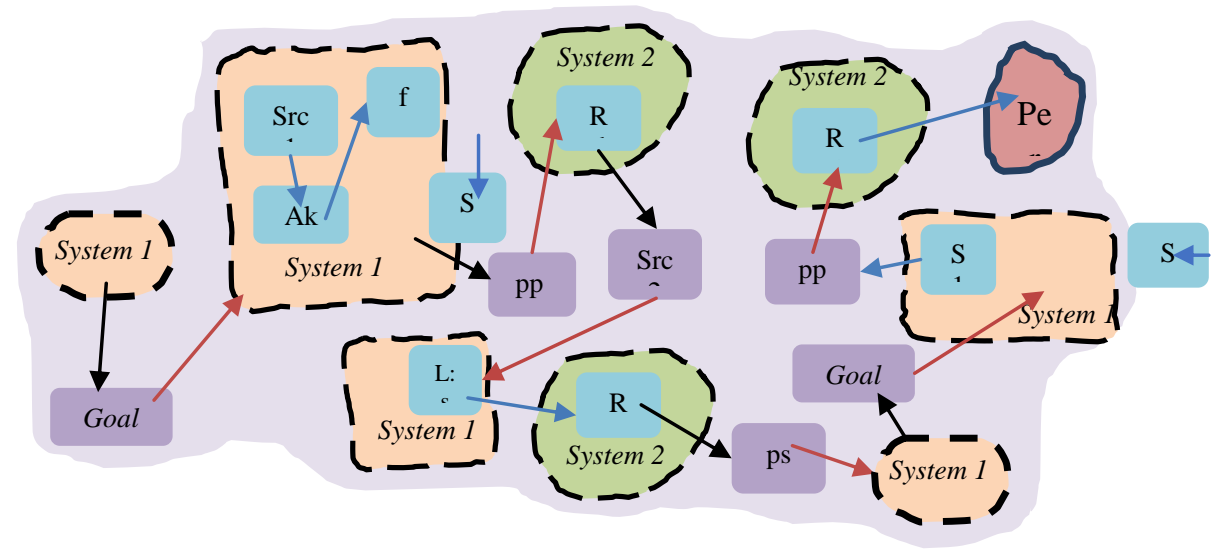

Figure 8

Schematic Thinking of subject 2

Table 3

Caption

\begin{tabular}{ll}
\hline \multicolumn{1}{c}{ Codes } & \multicolumn{1}{c}{ Meaning } \\
\hline $\mathrm{Src} 1$ & Creating a rectangular sketch image with caption $\mathrm{K}=12 \mathrm{~cm}^{2}$ \\
\hline $\mathrm{Ak}$ & Dividing the perimeter of the known side length \\
\hline $\mathrm{fp}$ & Writing the perimeter of a rectangular formula \\
\hline $\mathrm{Su}$ & Substitutingfor side length, namely 4 and 3 \\
\hline $\mathrm{ppp}$ & The perimeter of a rectangle \\
\hline $\mathrm{Rd}$ & Rereading the text of the problem intentionally/consciously \\
\hline $\mathrm{Src} 2$ & Creating a rectangular sketch image with caption $\mathrm{L}=12 \mathrm{~cm}^{2}$ \\
\hline $\mathrm{L}: \mathrm{s}$ & Dividing the area by the known side length \\
\hline $\mathrm{Ps}$ & Structure of the problem \\
\hline $\mathrm{Sq}$ & Writingthe formula of the perimeter of the square \\
\hline $\mathrm{S} 1$ & Substitutingthe side length, which is 4 \\
\hline $\mathrm{pp}$ & The perimeter of a quadrilateral \\
\hline $\mathrm{Goal}$ A & Aiming to produce the perimeter of a square \\
\hline $\mathrm{Goal} \mathrm{B}$ & Aiming to produce the perimeter of a rectangle \\
\hline Per & Doubtful \\
\hline System 1 & System 1 Process \\
\hline System 2 & System 2 Process \\
\hline & Process Transition to results \\
\hline & Process Transition to the next process \\
\hline
\end{tabular}


Subject 3 (High Level FOR)

Subject 3 was a subject with high FOR level. This was indicated by the absence of changes in answers, and the write-off of answers by the subject 3. After doing initial analysis that was shallow and produced a problem structure, system 1 subject 3 was active and decided to produce goal A. An indication of system 1 subject 3 producing goal A was that the square sketch was drawn with caption of area $12 \mathrm{~cm}^{2}$ and one of the side length was $4 \mathrm{~cm}$ by subject 3 . The following is the answer of subject 3 .

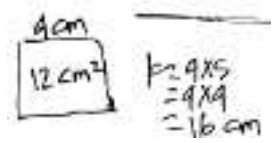

Figure 9

The Answer of Subject 3

After drawing a square sketch, subject 3 wrote $K=4 \times s=4 \times 4=16 \mathrm{~cm}$. The meaning of $K=4 \times s=4 \times 4=16 \mathrm{~cm}$ is the perimeter of the square equals four times its side length, so $4 \times 4$ produces 16 . Subject 3 did not realize that if the quadrilateral is a square with the length of side 4 , then it has $16 \mathrm{~cm}^{2}$. In fact, previously subject 3 wrote the area of a square in the sketch drawing, namely $12 \mathrm{~cm}^{2}$.

Subject 3 believed that if only information was given on one of the quadrilateral sides, then the quadrilateral is a square. When traced by interviews, the subject's belief was based on his learning experience. Subject 3 stated that the subject often encountered similar problems. When illustrated, the schematic thinking of subject 3 looks like the figure below.

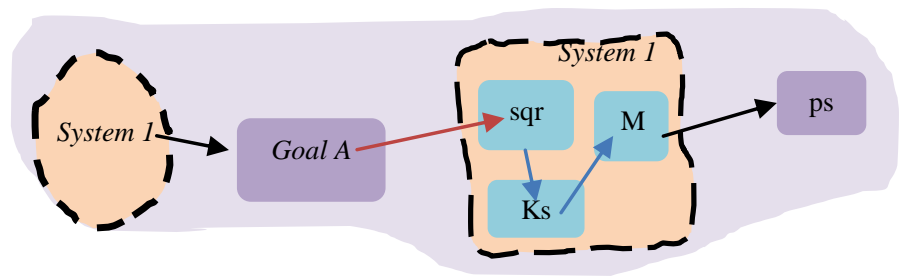

Figure 10

Schematic Thinking of Subject 3 
Table 4

Caption

\begin{tabular}{ll}
\hline \multicolumn{1}{c}{ Codes } & \multicolumn{1}{c}{ Meaning } \\
\hline sqr & Creating a square sketch image \\
\hline $\mathrm{Ks}$ & Writing the formula of the perimeter of a square \\
\hline $\mathrm{M}$ & Substituting the side length, which is 4 \\
\hline $\mathrm{ps}$ & The perimeter of a square \\
\hline Goal A & Aiming to produce the perimeter of a square \\
\hline System 1 & System Process 1 \\
\hline & ProcessTransition to results \\
\hline & ProcessTransition to the next process \\
\hline
\end{tabular}

\section{DISCUSSION}

There were indications that did not belong into two FOR level categories that have been formulated by previous researchers. Previous researchers categorized the level of FOR into two categories, namely high and low levels. The main indications that distinguish high and low FOR levels are the presence or absence of changes in answers (Ackerman \& Thompson, 2017; Brisson et al., 2018; Dujmović \&Valerjev, 2018; Swan et al., 2018). Medium FOR level, indicated by indications not included in the two categories, is named as FOR level in this research. The medium FOR level was indicated by the crossed out answers, objectives or goals changed, text problems read repeatedly, indecisive statements about the truth of the answers that have been generated, and doubts in determining the steps to be taken.

When reviewed with the three stage model (Pennycook, 2017), the indications for the medium level appear because active conflict-monitor detects conflict. Conflict-monitor is active in the second stage (Dujmović \& Valerjev, 2018; Handley \&Trippas, 2015). Conflict-monitor is a function of system 2 (Ackerman \& Thompson, 2017; De Neys, 2018). The active conflict-monitor is triggered by more than one response generated at the first stage. All of the responses generated in the first stage can be generated by system 1, or generated by system 1 and system 2 (De Neys, 2018; Dujmović \& Valerjev, 2018). In the three stage model, the third stage is the last stage, where decisions are made (Dujmović \& Valerjev, 2018; Handley \& Trippas, 2015).

The responses generated at the first stage, whether they were produced entirely by system 1 , or those produced by system 1 and system 2 , competed with each other in parallel. The responses competed to be chosen as responses which were represented as final answers. The responses produced at this first stage are called initial response (IR) (Ackerman \& Thompson, 2017; De Neys, 2018). IR goes into stage 2 based on priority. The priority is based on state of being confident about the suitability of the IR with the stimulus faced (Dujmović \& Valerjev, 2018; Swan et al., 2018). So, the response is believed to be in accordance with the stimulus, then the response will be prioritized to enter the second stage. 
Conflict-monitors are active, when there is more than one priority IR entering the second stage (Dujmović \& Valerjev, 2018; Swan et al., 2018). All of the processes occurred in the second stage were included into the system 2 process. When the analytical process by system 2 has been done on each IR priority, it will lead to several possibilities that can occur. First, each IR priority is believed to fit the stimulus and each priority IR supports each other. Second, each priority IR is not believed to be in accordance with the stimulus. Third, each priority IR is believed to be in accordance with the stimulus, but not mutually supportive or in conflict (conflict detected). Conditions that result in the medium FOR level are the second and third conditions.

Meanwhile, at a high FOR level, IR is generated in system 1 in the first stage and is directly selected as the final response without going through the second and third stages. This condition can occur in two possibilities, firstly because the stimulus faced is salience so that it attracts attention unconcious and a response is directly generated (Babai et al., 2015; Lamy et al., 2004; Lem, 2015; Zink et al., 2004 ). The second possibility is a familiar feeling towards the stimulus that is being faced so that the response is generated emotionally without analyzing (Fu et al., 2010; Mihaela \& Voica, 2008). Moreover, in previous researches conducted by experts, it is mentioned that at high FOR levels there is no change in answers and no re-analysis (Thompson et al., 2011, 2013; Thompson \& Johnson, 2014).

Further, at the low FOR level, more than one IR is generated in the first stage. After that, the priority IR enters the second stage before other IRs. Analysis of the priority IR on the second stage occurs and the results underlie decisions in the third stage. In the third stage, it is decided that priority IR is adequate and in accordance with the stimulus. Next, another IR enters the second stage and an analysis occurs. In the third stage, it is decided that IR is adequate and in accordance with the stimulus. Therefore, based on these conditions there is more than one response that results from different IRs that do not support each other. The responses are then analyzed in system 2 and the response that is considered most appropriate to the stimulus is chosen and is realized as the final answer.

Furthermore, FOR can be used to predict opportunities for re-analysis and answer changes (Thompson et al., 2011). Meanwhile, in solving problems, the answers generated are always influenced by FOR (Thompson et al., 2011; Thompson et al., 2013). On the other hand, FOR is also influenced by fluency in accessing learning experiences stored in long term memory. For this reason, from the perspective of educators, this FOR leveling can be used as a step to take action in learning problem solving. One of the actions that can be considered for educators based on this FOR level is intervention or schafolding to students in learning to solve problems. When learning to solve problems, students with adequate learning experience, FOR tends to be high, and vice versa. Therefore, with this levels of FOR, the right actions can be chosen by educators so that students do not experience difficulties in solving problems. 


\section{CONCLUSION}

There were three levels of feeling of rightness (FOR) students which were the findings in this research, namely low, medium, and high. Low FOR level was indicated by the answers being crossed out and the objectives or goals changed. The medium FOR level was indicated by the crossed out answers, changed goals or objectives, text of problems that was read over and over again, indecisive statements about the truth of the answers that have been generated, and doubts in determining what steps to take. High level FOR was indicated by answers that were not crossed and objectives or goals that were not changed.

Furthermore, by formulating the characteristics of these FOR levels, learning strategies that are in accordance with students' conditions can be chosen to minimize learning difficulties in solving mathematical problems, especially those related to the area and perimeter of polygon. The results of this research can also be used as consideration for developing learning models that refer to this FOR level. In addition, further research related to FOR is important to be carried out at a higher level because FOR determines the success of students in solving mathematical problems, especially when applied in daily life.

\section{REFERENCES}

Achmetli, K., Schukajlow, S., \& Rakoczy, K. (2018). Multiple solutions for real-world problems, experience of competence and students' procedural and conceptual knowledge. International Journal of Science and Mathematics Education, 17, 16051625 .

Ackerman, R., \& Thompson, V. (2017). Meta-reasoning: Monitoring and control of thinking and reasoning meta-reasoning: Monitoring and control of thinking and reasoning acknowledgments. Trends in Cognitive Sciences, 21(8), 607-617.

Babai, R., Shalev, E., \& Stavy, R. (2015). A warning intervention improves students , ability to overcome intuitive interference. ZDM Mathematics Education. 47(5), 735 745

Babai, R., Younis, N., \& Stavy, R. (2014). Involvement of inhibitory control mechanisms in overcoming intuitive interference. Neuro Education, 3(1), 1-9.

Bago, B., \& De Neys, W. (2017). Fast logic ? Examining the time course assumption of dual process theory. Cognition, 158, 90-109.

Banks, A. P., \& Hope, C. (2013). Heuristic and analytic processes in reasoning: An event-related potential research of belief bias. Psychophysiology, 51, 290-297.

Bellini-leite, S. C. (2017). Dual process theory: Systems, types, minds, modes, kinds or metaphors? A critical review. Review of Philosophy and Psychology, 9(2), 213-225

Borodin, A. (2016). The need for an application of dual-process theory to mathematics education. Cambridge Open-Review Educational Research e-Journal, 3, 1-31. 
Brisson, J., Schaeken, W., Markovits, H., \& De Neys, W. (2018). Conflict detection and logical complexity. Psychologica Belgica, 58(1), 318.

Căprioară, D. (2015). Problem Solving - purpose and means of learning mathematics in school. Social and Behavioral Sciences, 191, 1859 - 1864.

De Neys, W. (2012). Bias and conflict: A case for logical intuitions. Perspectives on Psychological Science, 7(1), 28-38.

De Neys, W. (2014). Conflict detection, dual processes, and logical intuitions: Some clarifications. Thinking \& Reasoning, 20(2), 169-187.

De Neys, W. (2018). Dual process theory 2.0 (First). New York: Routledge.

Dujmović, M., \& Valerjev, P. (2018). The influence of conflict monitoring on metareasoning and response times in a base rate task. Quarterly Journal of Experimental Psychology, 71(12), 2548-2561.

Durning, S. J., Dong, T., Artino, A. R., \& Schuwirth, L. (2015). Dual processing theory and experts' reasoning:exploring thinking on national multiple-choice questions. Perspective in Medical Education, 4(4), 168-175.

Evans, J. S. B. T. (2011). Dual-process theories of reasoning: Contemporary issues and developmental applications. Developmental Review, 31(2-3), 86-102.

Evans, J. S. B. T. (2012). Spot the difference: distinguishing between two kinds of processing. Mind\&Society, 11(1), 121-131.

Fu, Q., Dienes, Z., \& Fu, X. (2010). The distinction between intuition and guessing in the SRT task generation: A reply to Norman and Price. Consciousness and Cognition, 19(1), 478-480.

Handley, S. J., \& Trippas, D. (2015). Dual processes and the interplay between knowledge and structure: A new parallel processing model. Psychology of Learning and Motivation, 62, 33-58.

Imbir, K. K. (2016). New ideas in psychology from heart to mind and back again. A duality of emotion overview on emotion-cognition interactions. New Ideas in Psychology, 43, 39-49.

Kemendikbud. (2013). Kurikulum 2013 kompetensi dasar sekolah dasar (SD)/Madrasah Ibtidaiyah (MI). Jakarta: Kemendikbud.

Kow, K., \& Yeo, J. (2008). Teaching area and perimeter: Mathematics-pedagogicalcontent. Paper presented at the 31 st Annual Conference of the Mathematics Education Research Group of Australasia.

Kryjevskaia, M. (2014). Answer first: Applying the heuristic-analytic theory of reasoning to examine student intuitive thinking in the context of physics. Physics Education Research, 020109, 1-12. 
Lamy, D., Leber, A., \& Egeth, H. E. (2004). Effects of task relevance and stimulusdriven salience in feature-search mode. Journal of Experimental Psychology: Human Perception and Performance, 30(6), 1019-1031.

Lem, S. (2015). The intuitiveness of the law of large numbers. ZDM Mathematics Education. 47(5), 783-792.

Leron, U., \& Hazzan, O. (2009). Intuitive vs analytical thinking: Four perspectives. Educational Studies in Mathematics, 71(3), 263-278.

Lin, W., Lien, Y., \& Lin, W. (2013). The different role of working memory in openended versus closed-ended creative problem solving: A dual-process theory account. Creativity Research Journal, (May), 37-41.

Martin, J. W., \& Sloman, S. A. (2013). Refining the dual-system theory of choice. Journal of Consumer Psychology, 23(4), 552-555.

Mihaela, F., \& Voica, C. (2008). Between perception and intuition: Learning about infinity. Journal of Mathematical Behavior, 27, 188-205.

Musser, G. L., Burger, W. F., \& Peterson, B. E. (2011). Mathematics for elementary teachers a contemporary approach. United States of America: John Wiley \& Sons, Inc.

NCTM. (2000). Principles and standards for school mathematics. Reston, VA: The National Council of Teachers of Mathematics.

NCTM. (2009). Reasoning and sense making. Reston, VA: National Council of Teachers of Mathematics.

Pennycook, G. (2017). A perspective on the theoretical foundation of dual process models. In W. De Neys (Ed.), Dual process theory 2.0 (pp. 5-27). Routledge.

Prawita, W., Prayitno, B. A., \& Sugiyarto. (2019). Effectiveness of a generative learning-based biology module to improve the analytical thinking skills of the students with high and low reading motivation. International Journal of Instruction. 12(1), 14591476.

Mulligan, J., Prescott, A., Mithcelmore, M., \& Outrhed, L. (2005). Taking a closer look at students' images of area measurement. APMC.

Susiswo. (2015). Folding back mahasiswa dalam menyelesaikan masalah limit. Malang: Universitas Negeri Malang.

Swan, A. B., Calvillo, D. P., \& Revlin, R. (2018). To detect or not to detect: A replication and extension of the three-stage model. Acta Psychologica, 187, 54-65.

Tambychik, T., Subahan, T., \& Meerah, M. (2010). Students' difficulties in mathematics problem-solving:what do they say? Procedia-Social and Behavioral Sciences, 8(5), 142-151. 
Thompson, V. A., Pennycook, G., Trippas, D., \& Evans, J. S. B. T. (2018). Do smart people have better intuitions? Journal of Experimental Psychology: General, 147(7), 945-961.

Thompson, V. A., Evans, J. S. B. T., \& Campbell, J. I. D. (2013). Matching bias on the selection task: It's fast and feels good. Thinking and Reasoning, 19(3-4), 431-452.

Thompson, V. A., \& Morsanyi, K. (2012). Analytic thinking: do you feel like it? Mind \& Society, 11(1), 93-105.

Thompson, V. A., Prowse Turner, J. A. P., \& Pennycook, G. (2011). Intuition, reason, and metacognition. Cognitive Psychology, 63(3), 107-140.

Trippas, D., Thompson, V. A., \& Handley, S. J. (2017). When fast logic meets slow belief: Evidence for a parallel-processing model of belief bias. Memory \& Cognition, 45(4), 539-552.

Zink, C. F., Pagnoni, G., Martin-Skurski, M. E., Chappelow, J. C., \& Berns, G. S. (2004). Human striatal responses to monetary reward depend on saliency. Neuron, $42(3), 509-517$. 